\title{
The Case-agreement System in Subjunctive Complements
}

\author{
Feras Saeed * \\ (Qassim University, Saudi Arabia)
}

\begin{abstract}
Unlike matrix verbs, the verb in subjunctive complements in Standard Arabic lacks tense; nonetheless, it inflects for agreement and mood. The subject of subjunctive verbs is Case-marked accusative if it surfaces in a preverbal position; and nominative if it appears in a postverbal position. In addition, the subjunctive verb shows agreement asymmetry with its subject, depending on the position of the subject. Subjunctive complements appear in tenseless contexts in this language, i.e. control structures, ECM-like structures, and obviative structures. In this paper, I provide a new analysis for subject-verb agreement asymmetry in these complements and account for the different Case markers that appear on their subject. In particular, I argue that feature-specification on the inflectional head $\mathrm{T}$ triggers the verbal agreement asymmetry in subjunctive complements. I also argue that formal features and nominative Case in these complements can be valued by a defective probe. Crucially, I argue that the defective probe can establish agreement and assign nominative Case in-situ, without resorting to A-movement, and the subsequent movement of the embedded subject to a preverbal position is triggered by the EPP feature on the $\Phi$-complete T. The corollary of this investigation lends support to the assumption that the Case-agreement system in this language is not contingent on tense.
\end{abstract}

Keywords: subjunctive complements, defective probes, agreement, case, Standard Arabic

\section{Introduction}

Under minimalist assumptions, a complete probe can value formal features, i.e. $\Phi$-features on heads and structural Case on DPs, by means of applying the syntactic operation Agree. However, a defective probe cannot establish full agreement or assign structural nominative Case on goals (Chomsky, 2000):

(1) *I want he to come.

\footnotetext{
* Dr. Feras Saeed: Assistant Professor of Linguistics, Department of English, Unaizah Community College, Qassim University, Unaizah, Qassim, Saudi Arabia. E-mail: ferasaeed@yahoo.com.
} 
(2) *He asked she to leave.

The defectivity of a local probe makes the active argument in its domain an accessible target for a higher complete probe in order to assign the DP Case:

(3) I want him to come.

(4) He asked her to leave.

In non-null-subject languages, e.g. English, a complete probe is usually: i) $\Phi$-complete, and ii) tensed. Defective probes are both: i) $\Phi$-incomplete, with only [person] feature, and ii) tenseless.

The assumption that only $\Phi$-complete probes can assign nominative Case (Chomsky, 2000, 2001) seems to be problematic, in view of some empirical data of the Case-agreement system in Standard Arabic and similar null subject languages. In these languages, nominative Case on the subject can be assigned in-situ by a $\Phi$-incomplete probe:

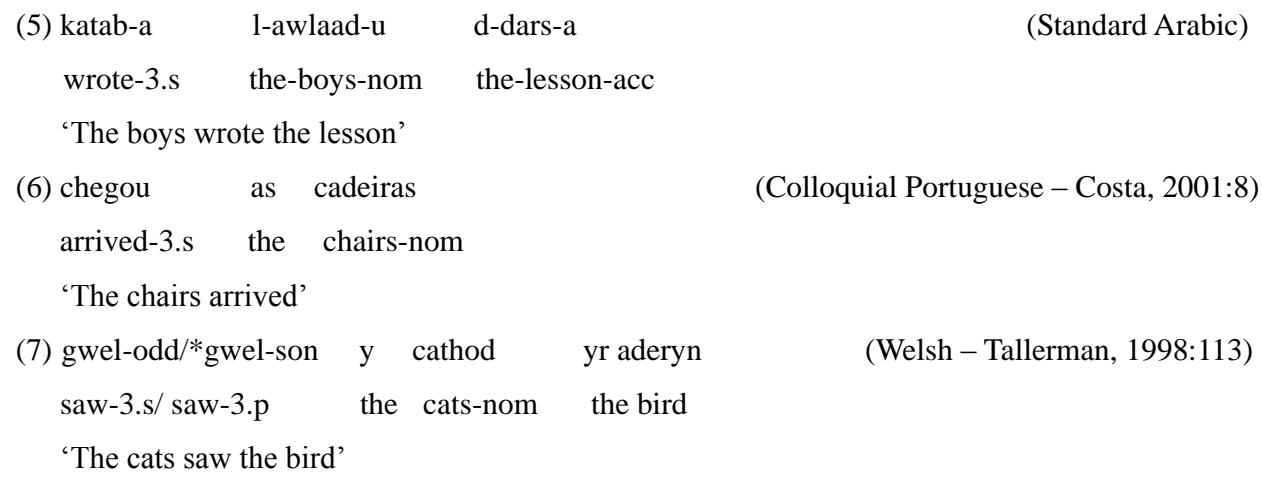

The examples in (5-7) show that a tensed probe, but $\Phi$-incomplete lacking plural number value, can assign nominative Case on DPs under partial agreement. However, it is difficult to speculate on the relation between tense and the Case-agreement system in these languages by examining tensed contexts only. A conclusive generalization on the correlation between tense and formal feature valuation in Standard Arabic and similar null subject languages would be better formulated if we look at the Case-agreement system in tenseless contexts.

\section{Tenseless structures in Standard Arabic}

A typical example of tenseless structures is sentential complementation and a regular structure of complementation in Standard Arabic is the subjunctive complement which is headed by functional particles, e.g. an, kay, li, and hatta, followed by an imperfective verb which inflects for agreement and mood:

(8) haawal-a 1-awlaad-u an yanaam-uu 


\section{Feras Saeed}

tried-3.s.m the-boys-nom to sleep-3.p.m.subj

'The boys tried to sleep'

(9) arad-tu Zayd-an an yahDur-a 1-ijtimaą-a

wanted-1.s Zayd-acc to attend-3.s.m.subj the-meeting-acc

'I wanted Zayd to attend the meeting'

Subjunctive complements in Standard Arabic surface in three different contexts, i.e. control structures, ECM-like structures, and obviative structures. In all three contexts, the verb lacks temporal distinction and depends on the tense of the matrix clause, but inflects for agreement:

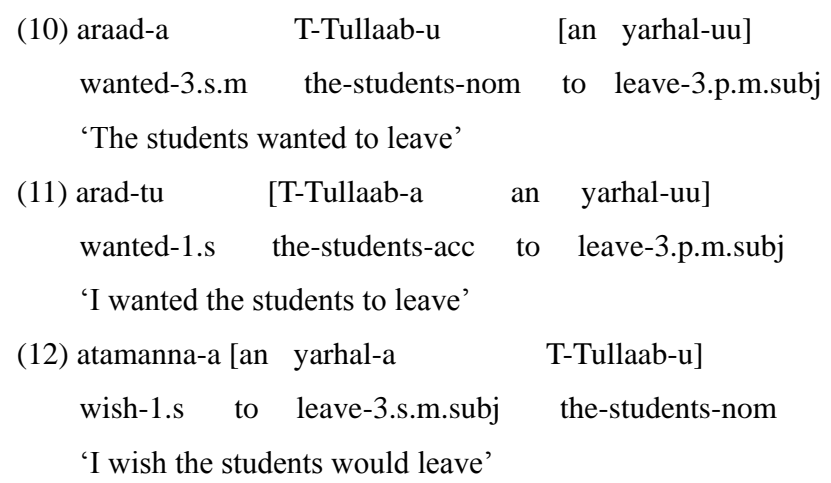

The multiple functions of subjunctive complements are not an exclusive property of Standard Arabic. It is argued that subjunctive complements in the Balkan languages, e.g. Modern Greek, Romanian, and Bulgarian, have multiple functions as well. It is remarked that infinitival complements do not exist in these languages, therefore, the subjunctive form is used in control structures as well as obviation structures (Dalmi, 2005:17-18):

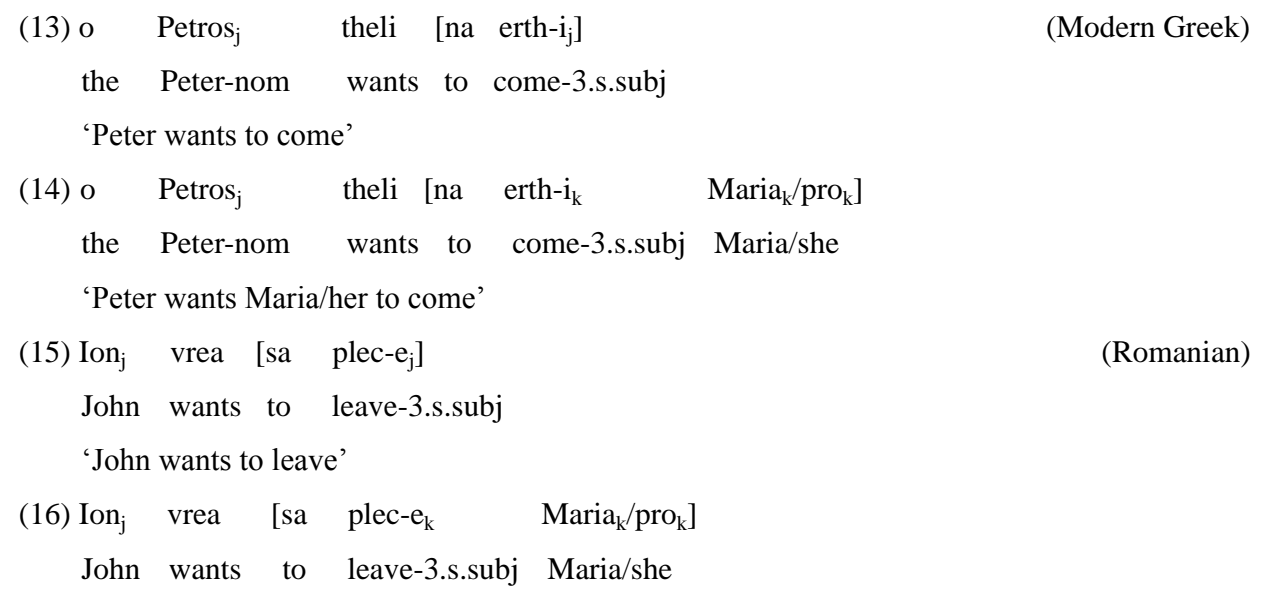


'John wants Maria/her to leave'

$$
\begin{aligned}
& \text { (17) } \left.\operatorname{Ivan}_{\mathrm{j}} \text { iska [da sledv-a }\right] \\
& \text { Ivan wants to study-3.s.subj } \\
& \text { 'Ivan wants to go to college' }
\end{aligned}
$$

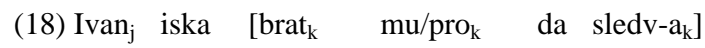

$$
\begin{aligned}
& \text { Ivan wants brother his/him to study-3.s.subj } \\
& \text { 'Ivan wants his brother/ him to go to college' }
\end{aligned}
$$

\section{Properties of subjunctive complements in Standard Arabic}

In this section, I examine the main properties of subjunctive complements in Standard Arabic and show that the major properties of these complements follow from the fact that their inflectional head can establish agreement and assign Case.

A notable property of subjunctive complements in Standard Arabic is that these clauses are headed by functional particles, like $a n,{ }^{\oplus}$ which have distinct distributional properties differentiating them from the standard complementisers in the language such as anna and inna:

$$
\begin{aligned}
& \text { (19) a. araad-a 1-walad-u an yathhab-a ila 1-madrasat-i } \\
& \text { wanted-3.s.m the-boy-nom to go-3.s.m.subj to the-school-gen } \\
& \text { 'The boy wanted to go to school.' } \\
& \text { b. *araad-a an al-walad-u yathhab-a ila 1-madrasat-i } \\
& \text { wanted-3.s.m to the-boy-nom go-3.s.m.subj to the-school-gen } \\
& \text { 'The boy wanted to go to school.' }
\end{aligned}
$$

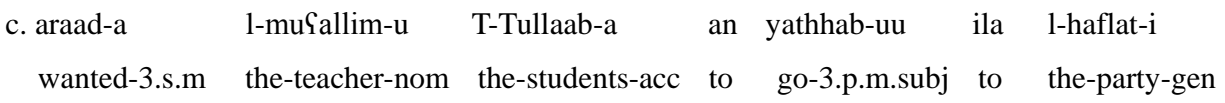

$$
\begin{aligned}
& \text { 'The teacher wanted the students to go to the party.' } \\
& \begin{array}{lllll}
\text { d. *araad -a } & \text { 1-muSallim-u } & \text { an } & \text { aT-Tullaab-a } & \text { yathhab-uu ila 1-haflat-i } \\
\text { wanted-3.s.m } & \text { the-teacher-nom } & \text { to } & \text { the-students-acc } & \text { go-3.p.m.subj to the-party-gen }
\end{array}
\end{aligned}
$$

The examples in (19) show that no lexical subject can intervene between the functional particle $a n$ and the verb in the embedded clause (Fassi Fehri, 1993; Soltan, 2007). If $a n$ were a complementiser, there would be no problem in placing the subject after the complementiser, as in the case with the complementiser anna:

\footnotetext{
(1) See Fassi Fehri (1993) and Soltan (2007) for the assumption that $a n$ is a complementiser.
} 


\section{Feras Saeed}

$$
\begin{aligned}
& \text { (20) a. dhann-a 1-muSallim-u [anna] T-Tullaab-a thahab-uu ila l-haflat-i } \\
& \text { thought-3.s.m the-teacher-nom that the-students went-3.p.m to the-party-gen } \\
& \text { 'The teacher thought that the students went to the party.' } \\
& \text { b.* dhann-a l-muYallim-u [an] aT-Tullaab-a thahab-uu ila 1-haflat-i } \\
& \text { thought-3.s.m the-teacher-nom to the-students went-3.p.m to the-party-gen } \\
& \text { 'The teacher thought that the students went to the party.' }
\end{aligned}
$$

It is well-established in the literature that complementisers in Standard Arabic mandate a strict SV word order in their complement (Fassi Fehri, 1993; Benmamoun, 2000). However, the example in (20 (b)) shows that when an takes an SV complement, the sentence is rendered ungrammatical, suggesting that an cannot be a complementiser.

It is also to be noted that the verb following the functional particle an lacks tense (Fassi Fehri, 1993; Soltan, 2007). If one assumes otherwise, we would expect such clauses to express tense:

$$
\begin{aligned}
& \text { (21) a. tamannai-tu an yahDur-a } \quad \begin{array}{l}
\text { 1-waziir-u } \\
\text { wished-1.s to attend-3.s.m the-minister-nom }
\end{array} \text { the-meeting-acc } \\
& \text { 'I wished the minister would attend the meeting' } \\
& \text { b.*tamannai-tu an haDar-a } \quad \text { 1-waziir-u } \\
& \text { wished-1.s to attend-3.s.m the-minister-nom } \\
& \text { 'I wished the minister attended the meeting' }
\end{aligned}
$$

Another property of subjunctive complements in Standard Arabic is that such structures can have a nominative subject (Fassi Fehri, 1993; Soltan, 2007):
(22) tawaqqa $-\mathrm{a}$
1-muSallim-u
an yajtaz-a
T-Tullaab-u
1-imtihaan-a
expected-3.s.m the-teacher-nom to pass-3.s.m.subj the-students-nom the-exam-acc
'The teacher expected the students to pass the exam.'

Moreover, subjunctive complements in this language inflect for agreement, and show an asymmetrical behaviour in agreeing with the subject of their clause, depending on whether the subject surfaces preverbally or postverbally:

$$
\begin{aligned}
& \text { (23) a. amar-tu [1-9ummaal-a an yarhal-uu] } \\
& \text { asked-1.s the-workers-acc to leave-3.p.m.subj } \\
& \text { 'I asked the workers to leave.' } \\
& \text { b. amar-tu } \quad \text { an yarhal-a } \\
& \text { asked-1.s to leave-3.s.m.subj }
\end{aligned}
$$

'I asked the workers to leave.'

Additionally, subjunctive complements in Standard Arabic never occur with the 


\section{The Case-agreement System in Subjunctive Complements}

complementiser anna 'that'. In this language, the complementiser anna always takes a tensed complement with an obligatory SV word-order (Fassi Fehri, 1993):

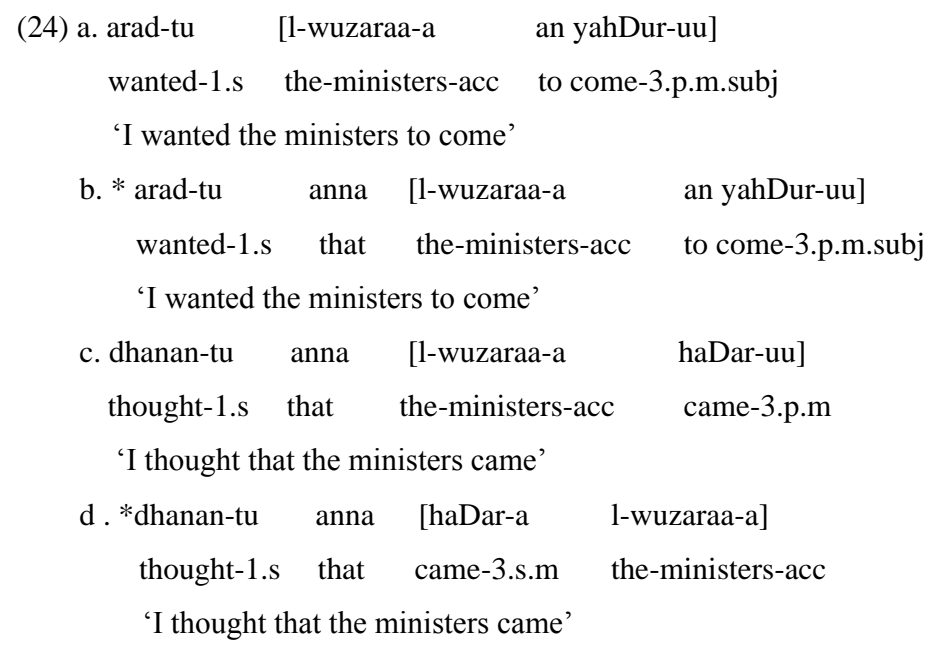

Moreover, it is argued that certain negation markers cannot surface in these complements (Fassi Fehri, 1993; Benmamoun, 2000; Soltan, 2007). I examine here three negation markers, namely lam 'did not', lan 'will not', and laa 'not'. It is to be noted that the first two markers, i.e. lam and lan occur only in tensed clauses; whereas the last negation marker laa can occur in tensed as well as tenseless contexts:

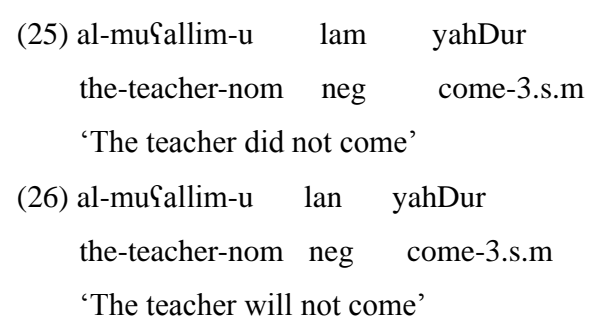

In the examples (25-26), the verb itself lacks temporal distinction. However, tense is encoded in the negation marker, and that is why these markers cannot occur in tenseless contexts (Fassi Fehri, 1993; Benmamoun, 2000; Soltan, 2007):
(27) *tawaqqaS-a 1-mu\{allim-u $\quad$ an lam yahDur aT-Tullaab-u $]$ expected-3.s.m the-teacher-nom to neg come-3.s.m the-students-nom
'The teacher expected that the students did not come.'
(28) *atamanna-a [an lan yahDur-a aT-Tullaab-u]
wish-1.s to neg come-3.s.m the-students-nom
'I wish the students would not come.' 


\section{Feras Saeed}

However, tenseless clauses can be negated by laa 'not' (Fassi Fehri, 1993; Benmamoun, 2000; Soltan, 2007):

$\begin{array}{ccccl}\text { (29) atamanna-a } & \text { [an } & \text { laa } & \text { yahDur-a } & \text { aT-Tullaab-u }] \\ \text { wish-1.s } & \text { to } & \text { neg } & \text { come-3.s.m } & \text { the-students-nom }\end{array}$

'I wish the students would not come.'

Essentially, the negation markers lam and lan can occur in embedded clauses, provided that these clauses are tensed:

$$
\begin{array}{llll}
\text { (30) adhunn-u anna T-Tullaab-a } & \text { lan } & \text { yahDur-uu } \\
\text { think-1.s that the-students-acc } & \text { neg } & \text { come.3.p.m } \\
\text { 'I think that the students will not come.' } &
\end{array}
$$

In fact, the behaviour of such negation markers and their markedness for tense can be found in other languages as well. In Kannada, the negation marker illa is argued to encode tense; and that it cannot be licensed in tenseless contexts (Amritavalli \& Jayaseelan, 2005:181-183):

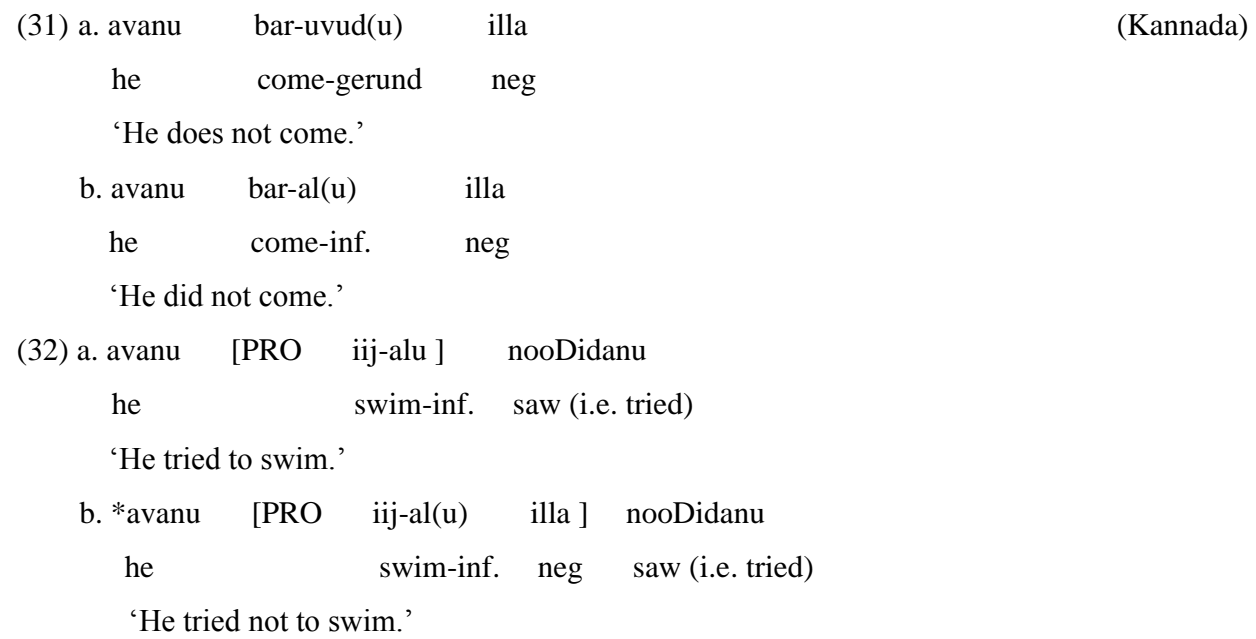

Amritavalli \& Jayaseelan (2005:183) argue that "if, as this shows, illa can occur only in finite clauses, it seems reasonable to say that it incorporates the notion of finiteness".

\section{Previous accounts}

Most of the previously proposed accounts for the Case-agreement system in Standard Arabic based their analysis on the empirical facts in independent and tensed sentences, without extending their account to clausal tenseless complements. However, two of these accounts have actually extended their proposed analysis of subject-verb agreement 


\section{The Case-agreement System in Subjunctive Complements}

asymmetry to subjunctive complements. In the following sub-sections, I review these two accounts.

\subsection{Fassi Fehri (1993)}

A pioneering approach to subject-verb agreement asymmetry in Standard Arabic is the 'rich-AGR analysis' proposed by Fassi Fehri (1993), where it is argued that the unmarked word-order in Standard Arabic is VS which is derived via movement of the verb to I and the alternative SV order is derived via raising the subject to spec-IP or spec-Agr if the IP is split.

Fassi Fehri argues that subject-verb agreement is established in a spec-head relation where $\Phi$-features on the head I can only be valued by argumental subjects. Expletive subjects, he argues, are not sufficient licensors of $\Phi$-features, although they may play an indirect role in the agreement system, particularly in partial agreement contexts.

Additionally, Fassi Fehri argues that partial agreement in VS sentences corresponds to the Agr being poor and that thematic DPs cannot be raised to spec-Agr when the Agr head is poor. Alternatively, thematic DPs must be raised to spec-Agr when the Agr head is rich.

He cites examples from different languages to the effect that sentences with postverbal subjects do not usually exhibit rich agreement (Fassi Fehri, 1993:34-36):

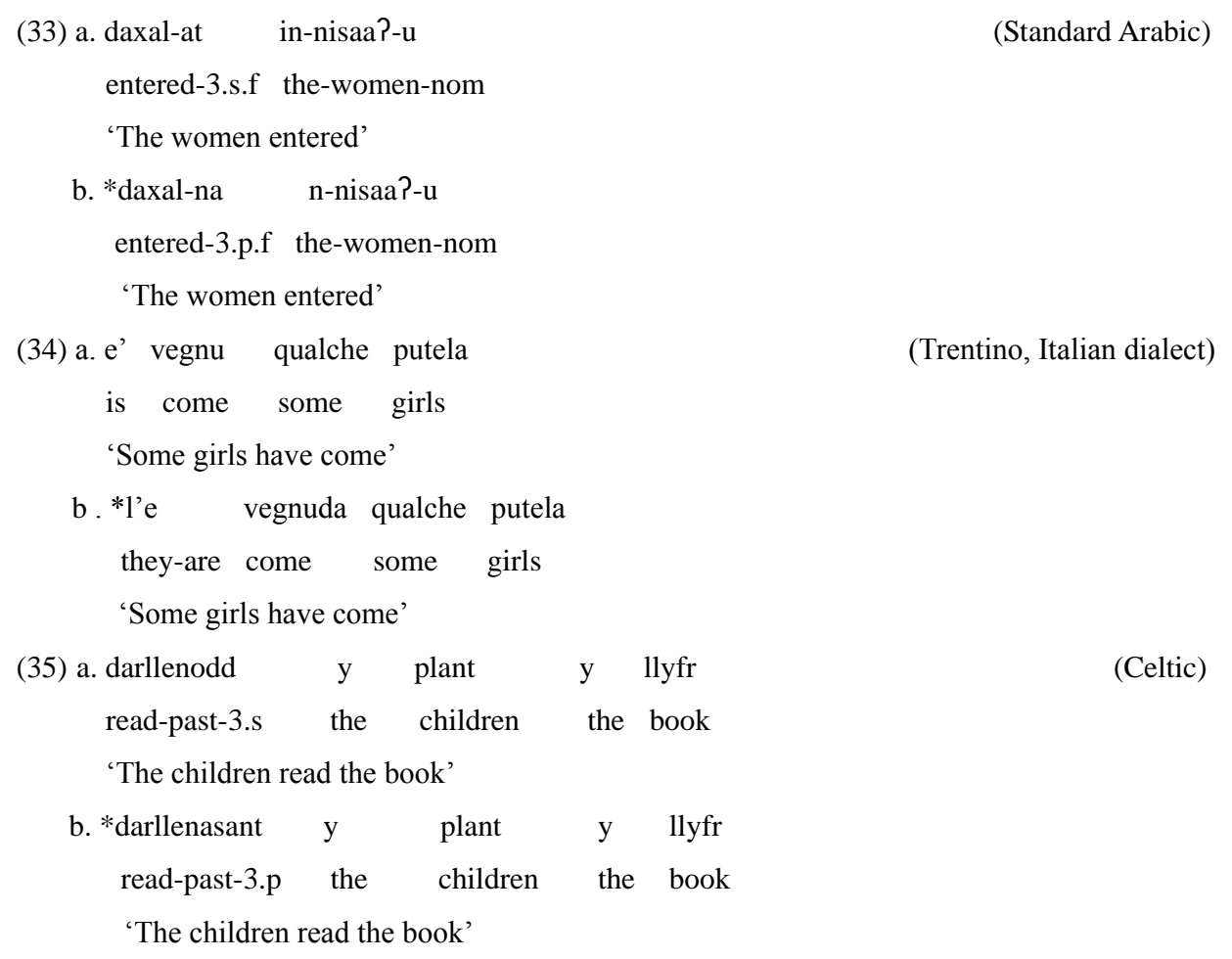




\section{Feras Saeed}

Fassi Fehri observes that postulating that postverbal subjects correspond to having a poor Agr cannot be always true. He notes that there are languages that exhibit rich Agr regardless of the position of the subject and whether it is postverbal or preverbal. Among these languages are most of the Arabic dialects. He cites examples from Moroccan Arabic and Standard Italian to this effect (Fassi Fehri, 1993:36-37):

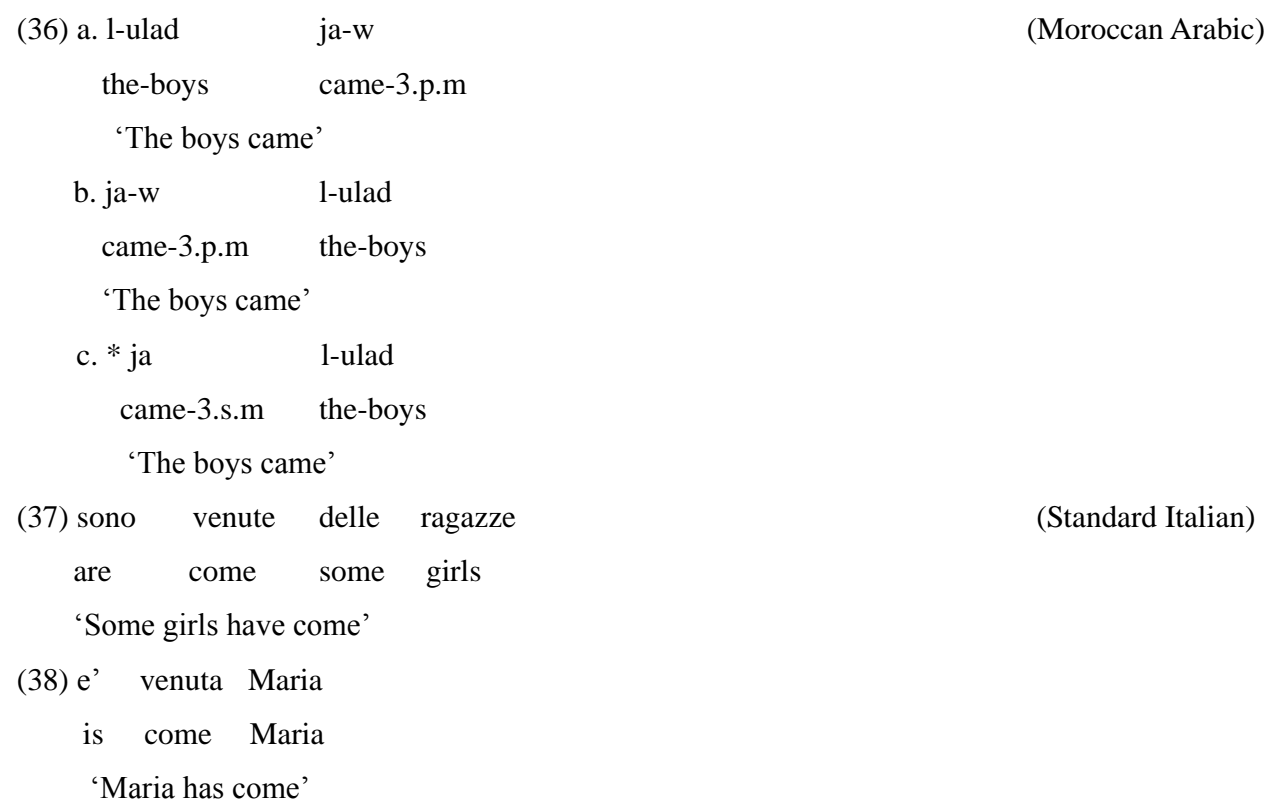

To regulate all these various instances of agreement, Fassi Fehri (1993:44) proposes a criterion which he calls 'the AGR criterion':

(39) AGR Criterion:

A. a specified Agr is licensed only by:

i) an argumental-NP in its spec; or

ii) an argumental-chain of which one member is in its spec.

B. an argumental-NP in spec-Agr is licensed only by rich Agr.

Thus, partial agreement is established in a spec-head configuration via a chain of which the head is an expletive in spec-AgrP and the tail is a thematic subject in spec-VP. Rich Agr occurs only if the subject precedes the verb, so that a spec-head configuration is established. Moreover, the relation between the position of the subject and the richness of Agr in Standard Arabic is interdependent in the sense that Agr is rich if the subject is fronted, and the subject is fronted if Agr is rich.

Full agreement in VS sentences in dialectal Arabic is explained by means of stipulating 
that rich Agr is activated through a chain of which the head is an expletive in spec-Agr and the tail is an argumental subject in spec-VP. Specification of features is argued to be an attribute of the head Agr, not the expletive.

Subjunctive complements, which are the structures under investigation in this paper, are assumed to be finite clauses headed by the complementiser an which is glossed in the examples as 'that' (Fassi Fehri, 1993:84, example (17)). Hence, subject-verb agreement asymmetry in these complements is analysed in a similar manner to that of matrix clauses. Accusative Case on the preverbal DP in subjunctive complements is argued to have been assigned by the matrix verb under government.

In fact, Fassi Fehri has captured a very important conclusion when he assumed that full or partial agreement corresponds to the availability of features on the inflectional head, however the adopted configuration could not help deliver a convincing and uniform mechanism that can account for the agreement facts in Standard Arabic.

To start with, the proposed spec-head configuration has been shown to be incapable of explaining the agreement asymmetry in this language without having to stipulate the existence of null expletives, a stipulation that lacks any empirical evidence. In fact, Fassi Fehri stresses that expletives cannot value agreement features, but the pitfall he has fallen into is proposing that expletives can activate agreement in an indirect way through their linkage with argumental subjects. It seems that the only motivation for this assumption is to establish a spec-head relation by proposing the existence of a null element in spec-Agr, though the agreement features on Agr are actually checked against those of the postverbal DP. Thus, this assumption seems to be construct-specific and has no other syntactic or semantic motivation.

Moreover, Fassi Fehri does not offer any explanation for the optionality in fronting subjects in dialectal Arabic and he merely stipulates that the expletive-NP chain seems to always value full agreement in these dialects.

Furthermore, one wonders how this analysis can explain the agreement facts in First Conjunct Agreement constructions in Standard Arabic where the verb either fully agrees with the first conjunct if the latter is pronominal or partially if it is nominal. A spec-head configuration for such constructions cannot be maintained, unless one assumes that the expletive is linked in this case only to the first conjunct; such an assumption cannot be maintained since the two conjuncts actually fully agree with the verb in SV order, and in dialectal Arabic the verb agrees fully with both conjuncts in VS order.

\subsection{Soltan (2007)}




\section{Feras Saeed}

Another approach that is proposed to account for the asymmetry in subject-verb agreement in Standard Arabic is the 'null pro analysis' by Soltan (2007). The proposed mechanism is based on the recent theories of agreement where the spec-head configuration is argued to be insufficient to explain the facts of agreement cross-linguistically, in favour of the operation Agree.

To explain the asymmetrical behaviour of subject-verb agreement in Standard Arabic in both word-order alternatives VS and SV, Soltan takes the absence of this asymmetry with pronominal subjects as his point of departure. He argues that in Standard Arabic the verb establishes full agreement with its pronominal subject, whether that subject is overt or null, in both word-orders ${ }^{\mathbb{1}}$ (Soltan, 2007:61):

$$
\begin{aligned}
& \text { (40) a. hum qara?-uu d-dars-a } \\
& \text { they read-3.p.m the-lesson-acc } \\
& \text { 'They read the lesson' } \\
& \text { b. qara?-uu hum d-dars-a } \\
& \text { read-3.p.m they the-lesson-acc } \\
& \text { 'They read the lesson' }
\end{aligned}
$$

After establishing that full agreement is required when the subject is pronominal, regardless of the word-order, Soltan argues that the word-order alternation in Standard Arabic, i.e. VS and SV, is not due to the presence/absence of subject movement, but is,

\footnotetext{
(1) Soltan seems to have overlooked the fact that in Standard Arabic overt pronominal subjects do not actually follow their verbs. When a pronominal DP is the thematic subject of the verb, it has to precede the verb or get dropped. The sentence becomes ungrammatical when the pronominal subject follows the verb (Fassi Fehri, 1993):
(i) * ji?-na hunna
came-3.p.f they-f
'They came'

However, an overt pronominal subject can follow the verb in two cases:

I. when the pronominal DP is a member of a conjoined phrase, for example:
(ii) jaa?-uu
hum wa Paxawat-u-hum
came-3.p.m they-m and sisters-nom-their

'They and their sisters came'

Here, the pronominal subject is a member of a conjoined phrase where the subject of the verb is the whole phrase, not the pronominal DP alone.

II. when the pronominal DP is followed by a negated phrase, for example:
(iii) jaa?-uu hum laa Paabaa?-u-hum
came-3.p.m they-m not fathers-nom-their
'They, not their fathers, came'

Here, the pronominal DP that follows the verb is not the thematic subject of the verb (Fassi Fehri, 1993). Such pronominals are treated in the literature as overt copies of the moved subject and usually are associated with emphasis/contrastive focus effect.
} 


\section{The Case-agreement System in Subjunctive Complements}

instead, 'a consequence of two different base-generated structural representations' (Soltan, 2007). Therefore, he assumes that Standard Arabic does not have any instance of A-movement. He claims that SV structures differ from VS structures in their syntactic, semantic and Case properties. He remarks that semantically the preverbal DP in SV order has been, traditionally, argued to have topical interpretation; whereas the postverbal DP in VS order receives thetic interpretation.

This claim, he argues, is supported by the fact that indefinite non-specific NPs cannot occur preverbally in Standard Arabic (Soltan, 2007:51):

$\begin{array}{rll}\text { (41) a. *walad-un } & \text { kasar-a } & \text { 1-baab-a } \\ \text { boy-nom } & \text { broke-3.s.m } & \text { the-door-acc }\end{array}$

'A boy broke the door'

b. kasar-a walad-un al-baab-a

broke-3.s.m boy-nom the-door-acc

'A boy broke the door'

According to Soltan, the requirement that preverbal subject DPs should be definite is similar to that of topics, suggesting that preverbal subject DPs are base-generated in a left-peripheral position, rather than being moved from within the vP. However, he does not discuss whether preverbal object DPs behave in a similar manner and whether topics in general are base-generated in a topic-position.

Moreover, he argues that wh-movement across a postverbal DP is possible, but this movement is not allowed across a preverbal DP (Soltan, 2007:52):

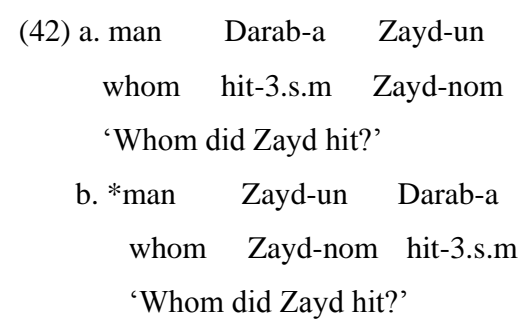

The ungrammaticality of (42 (b)) can be explained, according to Soltan, if one assumes that the DP in spec-TP is in an A-bar position, consequently blocking wh-movement under standard minimalist assumptions.

In addition to these differences between the SV and VS structures in Standard Arabic, Soltan points out that another empirical difference can be found in the Case properties of both structures. While postverbal DPs uniformly receive nominative Case, preverbal DPs receive nominative Case only in the absence of other Case-licensors like complementisers or 


\section{Feras Saeed}

verbs in ECM constructions (Soltan, 2007:53-54):

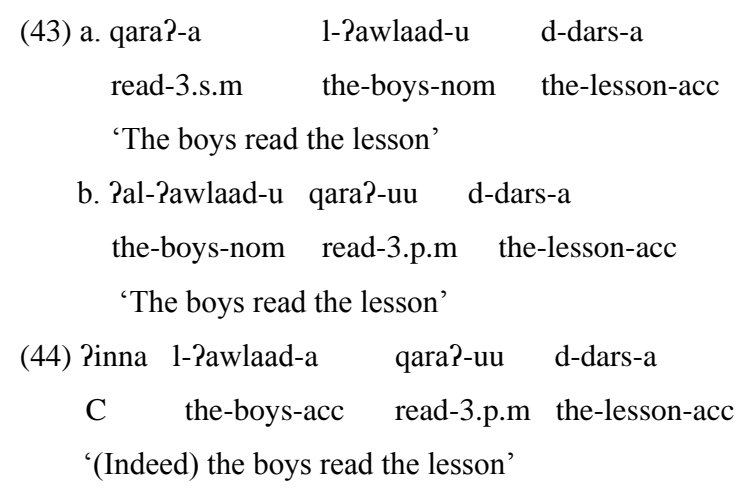

The data in (43-44), according to Soltan, denote that a postverbal DP always receives a nominative Case, whereas a preverbal DP receives a default nominative Case only as a last resort in the absence of any other Case-licensor.

On the basis of these empirical differences, Soltan (2007:60) argues that "while postverbal DPs are uncontroversially subjects, preverbal DPs exhibit the semantic and syntactic properties typically associated with topics/left-dislocated elements".

Furthermore, Soltan introduces two different underlying structures for SV and VS orders in Standard Arabic (2007:63):

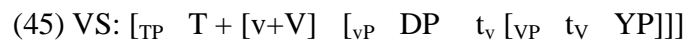

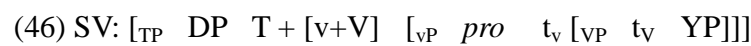

$\mathrm{He}$ argues that in VS structure the lexical postverbal DP is base-generated in spec-vP and remains in-situ. The VS order results from the movement of the verb from $\mathrm{V}$ to $\mathrm{v}$ and finally to T. Alternatively, spec-vP in SV structure is occupied by a null pro and the preverbal DP is base-generated in spec-TP. Therefore, spec-TP is taken to be a topic/CLLD position.

Agreement in SV order is assumed to be established when Agree takes place between the head $\mathrm{T}$ and a null pronominal. Full agreement in this word order is tied to the presence of a null subject pro in spec-vP. Rich agreement with pronominals, whether overt or null, is required, in order to identify and license pronominal DPs so that the derivation converges at the interface. The preverbal DP is base-generated in its surface position to satisfy the EPP feature on T. Moreover, the preverbal DP is assumed to be outside the search domain of the T probe, therefore it does not establish any agreement relation with the head $\mathrm{T}$, and it gets a default Case under the absence of any Case assigner.

Partial agreement in VS order is assumed to occur when Agree takes place between T and a lexical subject in spec-vP. In this word order, the head $\mathrm{T}$ is assumed to be specified only for 
gender feature. The nominative Case of the postverbal DP is assigned as a reflex of agreeing with the T probe.

Soltan extends his analysis to subjunctive complements in Standard Arabic, claiming that agreement asymmetry in these complements is triggered by the type of subject occupying spec-vP. If the vP-internal subject is a null pro, there is full agreement on the verb, however, if the subject is a nominal DP, the verb will show partial agreement.

Soltan's main focus in his discussion of these complements is to find out the syntactic position of the preverbal DP that surfaces in these complements and whether it has moved from spec-vP or base-generated, and to account for the accusative Case on this DP. He starts his discussion by assuming that the functional particle an in subjunctive complements is a complementiser and that there is no raising or A-movement in these complements or in Standard Arabic in general. Then, he claims that the preverbal DP in these complements is a thematic argument of the matrix verb that is base-generated in the specifier position of the matrix VP, which is above the embedded complementiser an, through a non-movement process called 'prolepsis' (2007:137). In this position, he argues, the matrix verb assigns the DP's accusative Case.

Thus, Soltan assumes that the alternation in word-order in Standard Arabic is not the result of a derivational operation whereby one word-order is derived from the other. Rather, he suggests that the VS and SV word orders correspond to the existence of two distinct structures in the language; consequently, there are no instances of A-movement and/or preverbal subjects in this language.

In the $8^{\text {th }}$ century, Arab grammarians denied the existence of preverbal subjects in Standard Arabic and suggested that word-order alternation in this language corresponds to the existence of two different structures (see Siibawayh, $8^{\text {th }}$ century). The VS structure was called 'the verbal clause' and the SV structure 'the nominal clause'. As a result, the preverbal DP was assumed to be a topic and A-movement of the subject to a preverbal position was rejected. Moreover, those grammarians suggested that the verb agrees with a null pro following the verb in the SV structure, not the surface preverbal DP. Hence, Soltan's analysis does not seem to offer any new account for subject-verb agreement asymmetry in the language. It seems to be merely a reproduction of the same old traditional account proposed by classical Arab grammarians.

To this effect, Fassi Fehri (1993:91) in his seminal work on the clause structure of Arabic has called this account 'incorrect' \& 'inaccurate' and encouraged a modern revision of this traditional view of verbal agreement in Standard Arabic: 


\section{Feras Saeed}

The Arabic dominant grammatical tradition of Basra has denied the subject interpretation. According to this tradition, a preverbal NP is always interpreted as a 'topic', i.e. a constituent in an A-bar position (see e.g. Siibawayh, $8^{\text {th }}$ century). Previous generative work has adopted (incorrectly) the Basrian's view (see e.g. Bakir, 1980; Fassi Fehri, 1981; \& Ayoub, 1982; among others). The Kuufa tradition admits the existence of preverbal subjects, but without convincing arguments (see e.g. Ibn Madaa, $12^{\text {th }}$ century). It is then an important contribution to Arabic linguistics to show that this view, which was dominant for centuries, is inaccurate.

Soltan argues that the preverbal DP in SV sentences is not the subject because this DP has the properties of topics or left-dislocated elements. One of these properties is definiteness. He argues that the preverbal DP in SV sentences has to be definite, while the postverbal DP in VS sentences can be definite or indefinite, concluding that preverbal DPs can be described as topics or left-dislocated DPs, but not subjects.

In his canonical work 'Sharh Alfiyyat Ibn Maalik', the well-known classical Arab grammarian (Ibn Aqiil, 14 ${ }^{\text {th }}$ century) noted that indefinite subjects can precede the verb in many contexts in Standard Arabic. Moreover, Fassi Fehri (1993:28) observes that "Arabic topics are necessarily definite, whereas preverbal subjects can be indefinite. Indefinite preverbal subjects cannot be non-specific, however. They have to be specific, generic or bound by a quantifier”. Fassi Fehri cites some examples to this effect (1993:28):

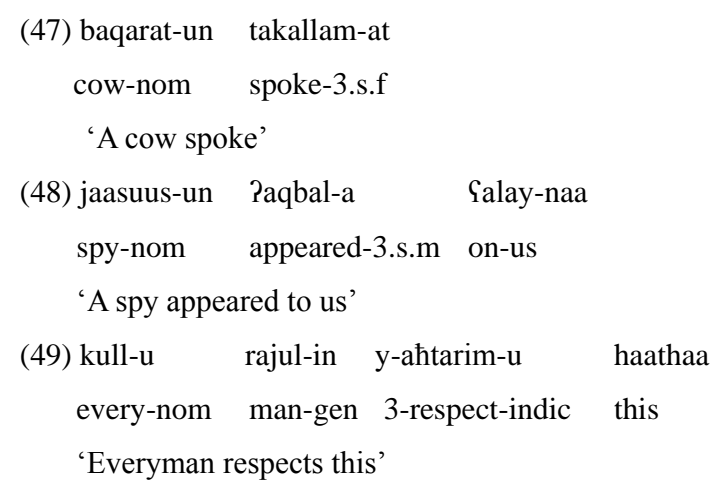

The examples in (47-49) show that Standard Arabic can have preverbal indefinite DPs. Moreover, it cannot be claimed that every preverbal definite DP is a topic ${ }^{\mathbb{1}}$. A definite DP is not necessarily a topic, for example the postverbal subject DP in VS order can be definite. Moreover, Fassi Fehri (1993) argues that subjects and topics differ with respect to their structural positions. Subjects occur within the domain of TP, whereas topics are outside this domain. He cites a number of diagnostic tests in support of this view. First, he argues that

\footnotetext{
(1) See Rizzi (2004) for his discussion of indefinite topics in Italian.
} 


\section{The Case-agreement System in Subjunctive Complements}

negation in Standard Arabic selects a TP in which the subject may surface preverbally (Fassi Fehri, 1993:30):

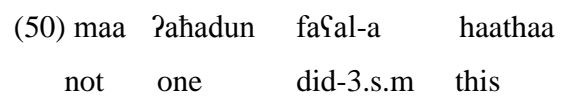

'No one did this'

On the other hand, a topic cannot surface inside a neg-phrase, as shown by the ungrammaticality of the sentence below:

$$
\begin{gathered}
\text { (51) *maa } \text { Zayd-an raPay-tu-hu } \\
\text { not } \quad \text { Zayd-acc } \\
\text { '(It is) not Zayd (that) I saw' }
\end{gathered}
$$

Another diagnostic test is the fact that a subject can be preceded by a question particle in Yes/No questions:

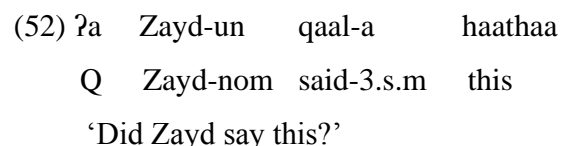

By contrast, a topic cannot be preceded by a question particle in Yes/No questions:

$$
\begin{array}{r}
\text { (53)*?a Zayd-un raPay-ta-hu } \\
\text { Q Zayd-nom saw-2.s-him } \\
\text { '(Is it) Zayd (that) you saw?' }
\end{array}
$$

Thus, it is clear that preverbal DPs in SV sentences are not necessarily topics, and that SV sentences can be derived by means of raising the vP-internal subject to spec-TP.

The basic assumption in Soltan's account is that the subject in Standard Arabic always stays in-situ in spec-vP. Preverbal DPs, according to this approach, are not subjects. Soltan's main argument is that full agreement in Standard Arabic can be established only with a postverbal pronominal subject whether that subject is overt or null. Now, if the above discussion regarding the legitimacy of having a preverbal subject is on the right track, then Soltan's analysis seems to be based on a misconception.

Another assumption in Soltan's analysis is that an argumental pronominal subject can occur postverbally. In fact, this is another misconception. Pronominal subjects in Standard Arabic do not follow the verb. They are either dropped, which is the general rule in the language, or raised to a sentence-initial position. Harbert and Bahloul (2002:49) argue that "Pronoun subjects in Arabic typically cannot appear postverbally, but are subject to obligatory fronting". Fassi Fehri (1993:98) argues that "nominative free forms (of pronominals) are normally found as subjects of nominal sentences or preverbal subjects" 


\section{Feras Saeed}

(italics mine). He also points out that "subject pronoun has to move preverbally to spec of Agr to meet the requirement for rich agreement" (1993:131). In addition, he emphasizes that "the co-occurrence of Agr(eement) and pronouns in postverbal position is barred" (1993:132).

Pronominal subjects can occur postverbally only in limited contexts where their movement is constrained due to their association with other structures. For example, a pronominal subject can occur postverbally if it is the first conjunct of a conjoined phrase:

(54) haDar-uu hum wa Paabaa?-u-hum
came-3.p.m they.m and fathers-nom-their

'They and their fathers came'

But, as Fassi Fehri argues, an independent pronominal subject cannot follow the verb (1993:108):

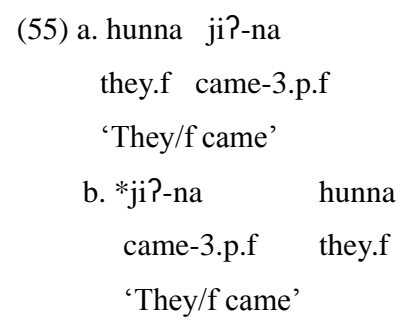

If this stream of argumentation is on the right track, as it seems to be, then Soltan's assumption, that pronominal subjects can follow the verb, is invalid. Further, since it is established that pronominal subjects can occur only preverbally, not postverbally, then Soltan's assumption that preverbal DPs are topics since they are definite is also invalid, because pronominals, by definition, are definite.

Moreover, Soltan assumes that in SV sentences the head T establishes full agreement with the null pro in spec-vP and that the EPP-feature on $\mathrm{T}$ is satisfied through base-generating a DP in spec-TP. If one accepts, for argument's sake, that overt pronominal DPs can follow the verb, as Soltan incorrectly assumes, then how does the EPP-feature get satisfied in VS sentences with an overt postverbal pronominal subject? Why cannot this type of sentences have a base-generated DP in spec-TP?

In addition, arguing that full agreement is established only if the subject is pronominal is suspicious on different grounds. First, there is no rule in the grammar that blocks full agreement with nominal DPs, and Soltan does not provide any explanation for this stipulation. Second, this stipulation fails to capture the agreement facts in dialectal Arabic, where nominal DPs in postverbal position establish full agreement with the verb. 
Moreover, the analysis does not provide any explanation for the empirical fact that the preverbal DP in SV sentences always shows agreement in all $\Phi$-features with the verb, though, as Soltan claims, it does not establish any relation with the inflectional head.

Furthermore, assuming that the functional particle an in subjunctive complements is a complementiser lacks any good argument, for if an is a complementiser, as Soltan argues, why cannot the preverbal DP follow it, since it is an obligatory rule in Standard Arabic that complementisers must be followed by a DP?

Finally, the account does not explain the apparent full agreement between the embedded verb in the subjunctive clause and the base-generated preverbal DP, which Soltan assumes to be in a position above the embedded head $\mathrm{C}$.

\section{The Case-agreement system in subjunctive complements in Standard Arabic}

Under minimalist assumptions, I assume that verbal agreement in subjunctive complements in Standard Arabic is established through the application of the syntactic operation Agree, within a c-command local domain. I argue that the embedded head T sends a probe to target the embedded vP-internal subject. The head T in Standard Arabic can have the following inventory of unvalued features: i) $\Phi$-features, and ii) the EPP-feature. When T is $\Phi$-complete, it must have an EPP-feature, subsequently the subject moves to spec-TP; however, when $\mathrm{T}$ is $\Phi$-incomplete, it cannot have an EPP-feature and the subject remains in-situ. Crucially, the head $\mathrm{T}$ is considered $\Phi$-complete only when all the unvalued features available to that head enter the derivation unvalued and then assigned values in the syntax.

It is argued that there are three major classes of verbs in Standard Arabic that can subcategorise for subjunctive complements (Fassi Fehri, 1993; Benmamoun, 2000; Soltan, 2007). The first class includes matrix verbs such as araad 'wanted' and haawal 'tried', which require obligatory coreference between a matrix argument and the embedded subject/PRO (control structures). The second class includes matrix verbs like tawaqqaS 'expected' and amar 'asked/ordered', which allow a disjoint subject for the embedded clause which can be exceptionally Case-marked by the matrix verb when raised to a preverbal position in its clause (ECM-like structures). The third class includes matrix verbs such as tamanna 'wished' and raghib 'desired', which allow a disjoint subject for the embedded clause, but the subordinate clause should obligatorily have a strict VS order (obviation structures).

In the following sub-sections, I examine the agreement system in the three types of subjunctive complements in Standard Arabic: i) complements of control structures, ii) 


\section{Feras Saeed}

complements of ECM-like structures, and iii) complements of obviation structures.

\subsection{Complements of control structures}

We can differentiate between the three types of subjunctive complements on the basis of the properties of their subject DPs, i.e. presence/absence of overt subjects, Case on the subject, and position of the subject. While all three types are introduced by functional particles like an, followed by a verb which inflects for agreement, two types only can have overt subject DPs:

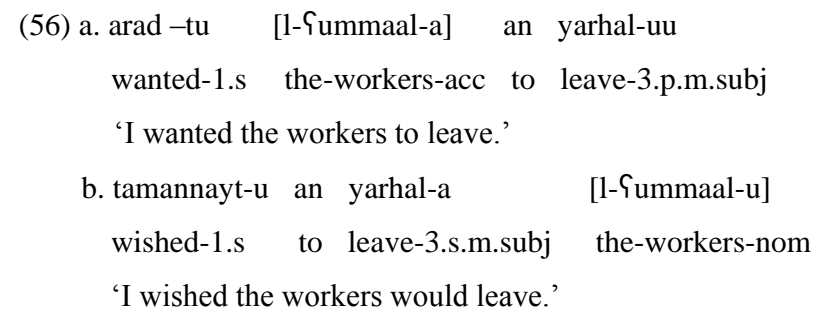

It is to be noted that in (56) the embedded clause surfaces with an overt subject DP that appears preverbally in (a) and postverbally in (b). Consequently, the Case of the subject varies depending on its position. An account of the Case-agreement system of these two types of complementation will be discussed in detail in the second and third sub-sections below.

However, the third type of subjunctive complements in Standard Arabic cannot have an overt subject DP and often patterns with control structures:

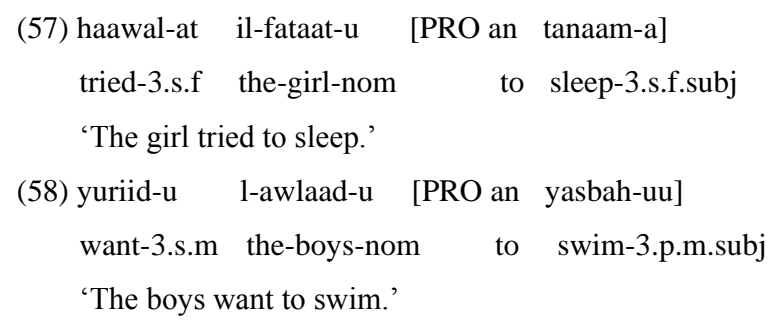

In this sub-section, I show that the embedded clauses in (57-58) function as complements of control structures. I assume that the non-lexical subject of the complement is PRO, which receives a distinct theta-role but is coreferenced with a higher argument (Chomsky \& Lasnik, 1993; Kayne, 1991). Consider the following example:

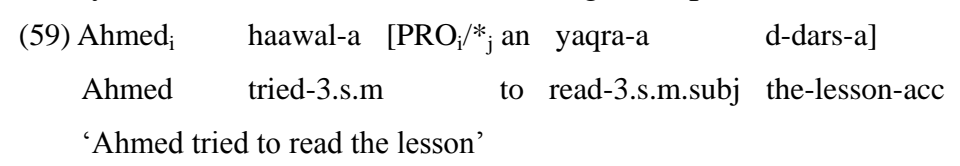

As the indexing of the example above indicates, the embedded null subject is referentially 


\section{The Case-agreement System in Subjunctive Complements}

dependent on the matrix subject and must be indexed with it, suggesting that it is not the null pronominal pro one expects to find in a null subject language like Standard Arabic.

In fact, the embedded subject position of this construction cannot be occupied by any lexical subject whether in a preverbal or a postverbal position (Fassi Fehri, 1993; Soltan, 2007):

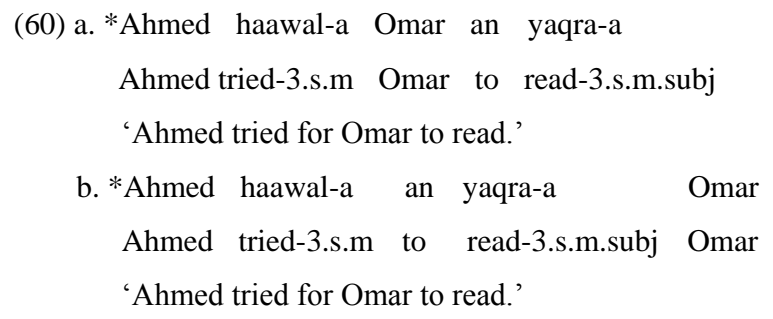

It is to be noticed that pro can occur in the subjunctive complement of the ECM-type and the obviation type; but PRO can occur only in the subjunctive complement of control structures. This difference is borne by the fact that Standard Arabic is a null subject language, where the subject DP can be dropped optionally:

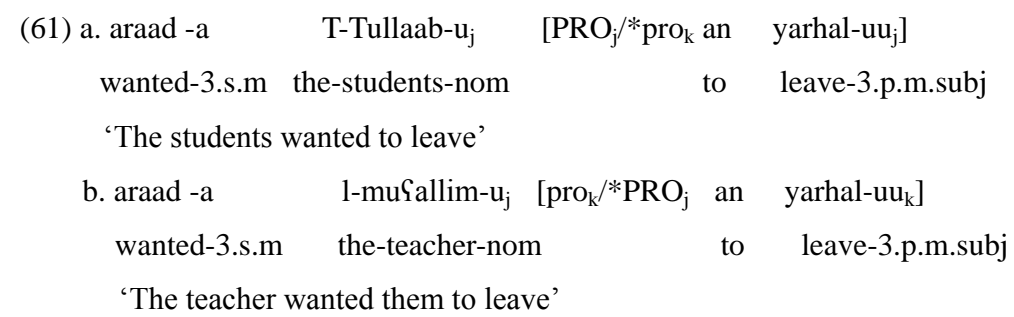

Another empirical evidence for the fact that the subject is actually PRO in control complements can be detected in the agreement morphology. While the embedded verb in ECM-like structures and obviation structures does not agree with the matrix subject, the embedded verb in control structures must agree with the matrix subject:

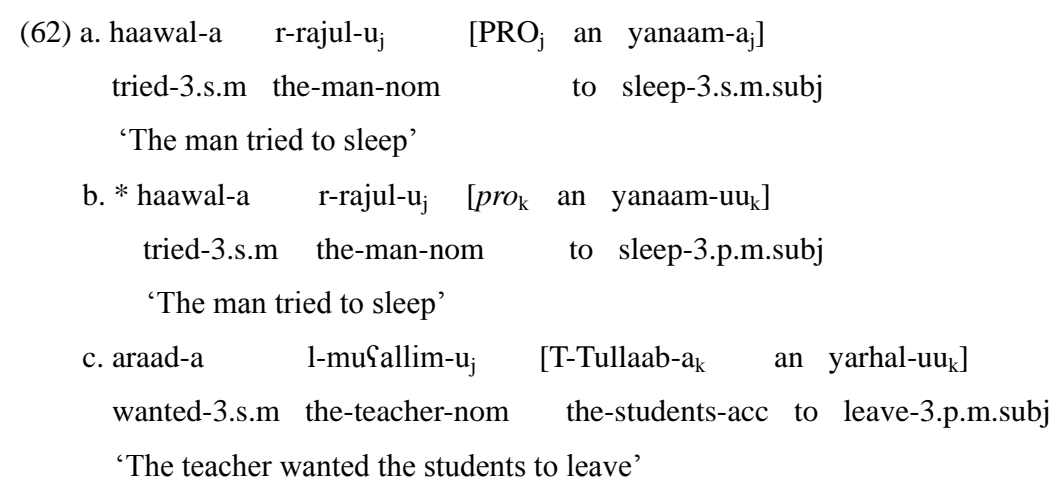




\section{Feras Saeed}
d. *araad-a $\quad$ 1-muSallim- $\mathrm{u}_{\mathrm{j}} \quad$ [T-Tullaab- $\mathrm{a}_{\mathrm{k}} \quad$ an yarhal- $\left.\mathrm{a}_{\mathrm{j}}\right]$
wanted-3.s.m the-teacher-nom the-students-acc to leave-3.s.m.subj
'The teacher wanted the students to leave'
e. tamanna-a l-muYallim-uun $\mathrm{j}_{\mathrm{j}} \quad\left[\begin{array}{lll}\mathrm{an} & \text { yarhal }^{-\mathrm{a}_{\mathrm{k}}} \quad \mathrm{T} \text { Tullaab- } \mathrm{u}_{\mathrm{k}}\end{array}\right]$
wished-3.s.m the-teachers-nom to leave-3.s.m.subj the-students-nom
'The teachers wished the students would leave'

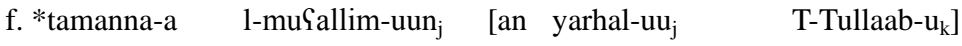
wished-3.s.m the-teachers-nom to leave-3.p.m.subj the-students-nom
'The teachers wished the students would leave'

Let us examine the following embedded complements in Standard Arabic:

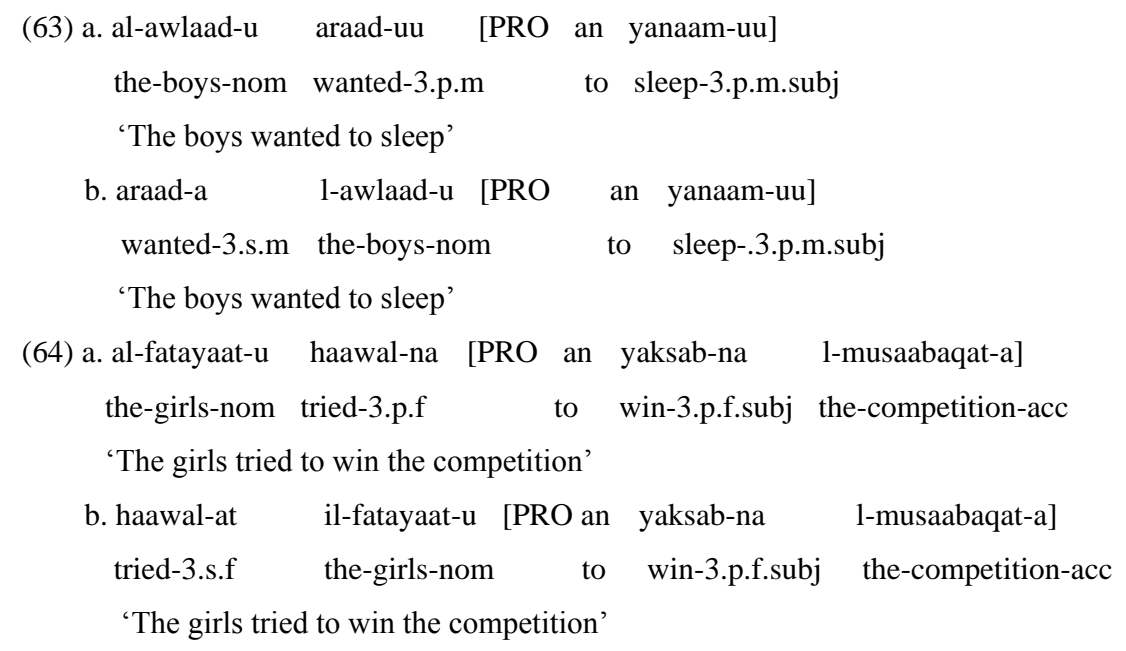

I argue that the embedded clauses in (63-64) belong to the control structure type, where the clause is headed by the functional particle an. I assume that agreement on the embedded verb is established between the embedded $\mathrm{T}$ and PRO. The probe of the embedded $\mathrm{T}$ targets PRO and values the former's $\Phi$-features, under identification with the matrix subject. Consequently, the probe of the embedded T establishes full agreement with PRO and assigns its null Case. It is argued that control structures pattern with finite clauses where the head $\mathrm{T}$ is selected by C, hence $\Phi$-complete (Chomsky, 2000, 2001).

\subsection{Complements of ECM-like structures}

ECM structures are characterized by the ability of their matrix verbs to assign an accusative Case to the subject of the embedded clause:

(65) I want [him to be smart].

(66) He asked [her to leave]. 
In (65-66), the subject of the embedded clause surfaces with an accusative Case assigned by the probe of the matrix verb. The EPP feature on the embedded $T$ forces the subject of the embedded clause to move from its base-position in spec-vP to spec embedded $\mathrm{T}$, raising the embedded subject into the local domain of the probe of the matrix verb.

In a language like English, a class of verbs like 'believe' and 'think' can subcategorise for a CP headed by an overt complementiser as in the examples below:

(67) The guard believes that the children broke the windows.

(68) He thought that he can win the competition.

In (67-68), the matrix verbs selects a $\mathrm{CP}$ with a finite embedded $\mathrm{T}$ and the nominative Case of the embedded subject is assigned by the probe of the embedded $\mathrm{T}$.

Some other verbs can also subcategorise for a $\mathrm{CP}$ headed by a null complementiser, which can assign the Case of the subject of its complement as accusative. This structure is called the 'for-to construction':

(69) I want (for) him to be happy.

The matrix verbs cited in (67-69) subcategorise for a CP and do not function as exceptional Case marking predicates in these environments. The property of exceptionally Case-marking an embedded DP as accusative gets activated when this class of verbs subcategorise for a TP:

(70) They believe him to be smart.

(71) Mary asked him to come.

In (70-71), the ECM verb selects a TP; hence no phase head to block the probe of the matrix verb from targeting the embedded subject. Further, the embedded $\mathrm{T}$ is defective and cannot assign Case to its subject. However, infinitival complements can have an EPP feature (Chomsky, 2000, 2001) which triggers the movement of the embedded subject to the specifier position of the embedded TP, making it possible for the probe of the matrix verb to assign the Case of the embedded subject as accusative.

Likewise, in Standard Arabic, a class of verbs, e.g. dhanna 'thought', xaala 'imagined', and iStaqada 'believed', can subcategorise for a CP in which the phase head $\mathrm{C}$ blocks the probe of the matrix verb from targeting the embedded subject. However, the Case of the embedded subject is marked accusative:

\footnotetext{
(72) dhann-a 1-haaris-u anna l-awlaad-a kasar-uu n-naafithat-a thought-3.s.m the-guard-nom that the-boys-acc broke-3.p.m the-window-acc

'The guard thought that the boys broke the window'
} 


\title{
Feras Saeed
}

\author{
(73) yaStaqid-u n-naas-u anna l-luSuuS-a harab-uu min as-sijn-i \\ believe-3.s.m the-people-nom that the-thieves-acc escaped-3.p.m from the-prison-gen \\ 'The people believe that the thieves escaped from prison'
}

In (72-73), there is a complementiser anna heading the embedded clause. Since the matrix verbs select a CP, consequently a finite TP, subject-verb agreement in their embedded clauses is established uniformly through the application of the syntactic operation Agree. It is to be noticed that in Standard Arabic the Case of the preverbal subject of the embedded clause is always accusative, when preceded by a complementiser. It is argued that complementisers in Standard Arabic have a strong accusative Case to discharge (Fassi Fehri, 1993; Benmamoun, 2000). The complementiser discharges its Case on the nearest DP, which happens to be in the specifier position of the embedded TP, marking it accusative.

Moreover, complementisers in this language mandate a strict SV word order in their complement (Fassi Fehri, 1993; Benmamoun, 2000). It seems that since $\mathrm{C}$ selects TP in finite clauses (Chomsky, 2000, 2001), the former selects a $\Phi$-complete T, with the EPP feature, which can trigger the movement of the subject to the specifier position of embedded TP; thus, creating the environment for the complementiser to discharge its Case there. Complementisers in Standard Arabic have an accusative Case that needs to be discharged on an adjacent DP, and this fact can be seen in other constructions in the language:

$$
\begin{aligned}
& \text { (74) al-walad-u mariiD-un } \\
& \text { the-boy-nom sick-nom } \\
& \text { 'The boy is sick' } \\
& \text { (75) inna l-walad-a mariiD-un } \\
& \text { C the-boy-acc sick-nom } \\
& \text { 'Indeed, the boy is sick' }
\end{aligned}
$$

The class of verbs described in this sub-section can also subcategorise for a CP headed by a null complementiser:

$$
\begin{array}{rllll}
\text { (76) dhann-a } & \text { 1-haaris-u } & \text { 1-awlaad-a } & \text { kasar-uu } & \text { n-naafithat-a } \\
\text { thought-3.s.m } & \text { the-guard-nom } & \text { the-boys-acc } & \text { broke-3.p.m } & \text { the-window-acc }
\end{array}
$$

'The guard thought the boys broke the window'

$$
\begin{array}{lllll}
\text { (77) yaStaqid-u } & \text { n-naas-u } & \text { 1-luSuuS-a } & \text { harab-uu } & \min \text { as-sijn-i } \\
\text { believe-3.s.m } & \text { the-people-nom } & \text { the-thieves-acc } & \text { escaped-3.p.m } & \text { from the-prison-gen }
\end{array}
$$

'The people believe the thieves escaped from prison'

In (76-77) the embedded clauses show a pattern of agreement, word-order, and Case assignment, similar to the ones headed by overt complementisers. Empirical evidence for the 


\section{The Case-agreement System in Subjunctive Complements}

existence of a null complementiser heading the embedded clauses above can be seen in the compulsory SV word order in these embedded clauses:

$$
\begin{aligned}
& \text { (78) *yaStaqid-u n-naas-u harab-a } \quad \text { l-luSuuS-u } \min \text { as-sijn-i } \\
& \text { believe-3.s.m the-people-nom escaped-3.s.m the-thieves-nom from the-prison-gen } \\
& \text { 'The people believe the thieves escaped from prison' }
\end{aligned}
$$

In (78), the embedded clause has a VS order. The verb in the embedded clause is tensed and agrees partially with its subject. It would be difficult to explain the ungrammaticality of the sentence above, if one denies the existence of a null complementiser heading the embedded clause and mandating a strict SV order of its complement. Thus, the ungrammaticality of (78) can be explained by assuming that there is a null complementiser heading a tensed embedded clause with a $\Phi$-complete T. Consequently, $\Phi$-completeness on the embedded T forces the embedded subject to move to the specifier position of the embedded TP to satisfy the EPP feature, and in this position the embedded subject becomes adjacent to the null complementiser so that the latter can discharge its accusative Case, therefore, the failure of the embedded subject to move to spec-TP is behind the ill-formedness of the sentence.

Another piece of empirical evidence for null complementisers can be detected in the compulsory accusative Case on the subject of the embedded clauses:

$$
\begin{aligned}
& \text { (79) *dhann-a 1-haaris-u l-awlaad-u kasar-uu n-naafithat-a } \\
& \text { thought-3.s.m the-guard-nom the-boys-nom broke-3.p.m the-window-acc } \\
& \text { 'The guard thought the boys broke the window' } \\
& \begin{array}{llllll}
\text { (80) *yaStaqid-u } & \text { n-naas-u } & \text { 1-luSuuS-u } & \text { harab-uu } & \min & \text { as-sijn-i } \\
\text { believe-3.s.m } & \text { the-people-nom } & \text { the-thieves-nom } & \text { escaped-3.p.m from } & \text { the-prison-gen }
\end{array}
\end{aligned}
$$

The two sentences in (79-80) are ungrammatical, because of the nominative Case on the subject of the embedded clause, suggesting that a null complementiser must be preceding these subjects, which, in turn, needs to assign accusative Case on an adjacent DP.

The possibility that such embedded clauses are TPs, in which the accusative Case on the preverbal subject is assigned by the probe of the matrix verb, can be ruled out on two grounds: i) the optionality of inserting an overt complementiser in these contexts; and ii) the impossibility of having a postverbal nominative subject in these tensed clauses, which is the unmarked option. The mandatory SV word order in these complements cannot be attributed to the defectivity of the embedded T, since these clauses are tensed and Standard Arabic can have tenseless complements in which the subject is postverbal and Case-marked nominative. This class of verbs can also have ECM-like properties where such predicates subcategorise 


\section{Feras Saeed}

for a TP in which the embedded subject surfaces with an accusative Case assigned by the probe of the matrix verb:

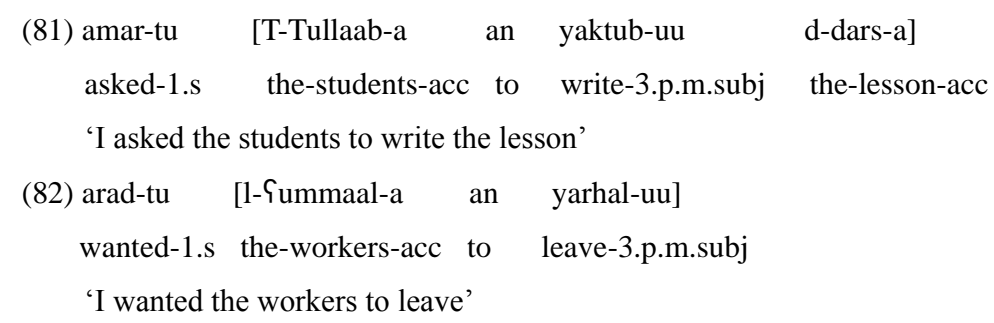

It is to be noted that a distinctive property of ECM-like structures in Standard Arabic is that such structures can have either an overt subject or a null pro:

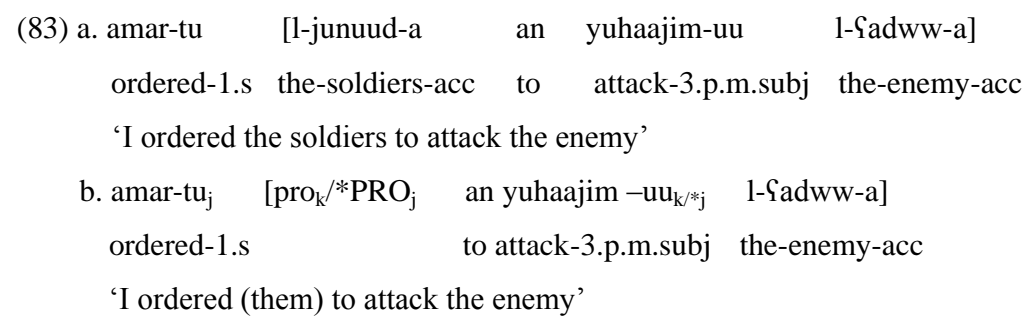

As the indexing in (83) indicates, the embedded null subject is referentially disjoint from the matrix subject, suggesting that such clauses pattern with ECM structures, and that they are different from the first type of subjunctive complements that is discussed in the previous sub-section, which patterns with control structures. Thus, I assume that in this structure the subject of the embedded clause is raised to the specifier position of embedded TP, to satisfy the EPP feature on the $\Phi$-complete $\mathrm{T}$, where it surfaces overtly with accusative Case assigned by the probe of the matrix verb or gets dropped in the course of computation.

It is to be noted that the subject of the embedded clause in ECM-like complements does not always undergo raising to the object position of the matrix verb. Therefore, when the embedded subject occurs postverbally, it surfaces with a nominative Case (Soltan, 2007):
(84) amar-tu [an yaktub-a T-Tullaab-u d-dars-a $]$
asked-1.s to write-3.s.m.subj the-students-nom the-lesson-acc
'I asked the students to write the lesson'
(85) araad-a 1-mudiir-u [an yarhal-a
wanted-3.s.m the-manager-nom to leave-3.s.m.subj the-workers-nom
'The manager wanted the workers to leave'

I argue that the embedded clauses in (84-85) are tenseless subjunctive complements of the ECM-like type, in which the nominative Case on the embedded subject is assigned by the 


\section{The Case-agreement System in Subjunctive Complements}

probe of the embedded T under agreement. I claim that in Standard Arabic and similar null subject languages nominative Case is assigned under agreement, not tense:

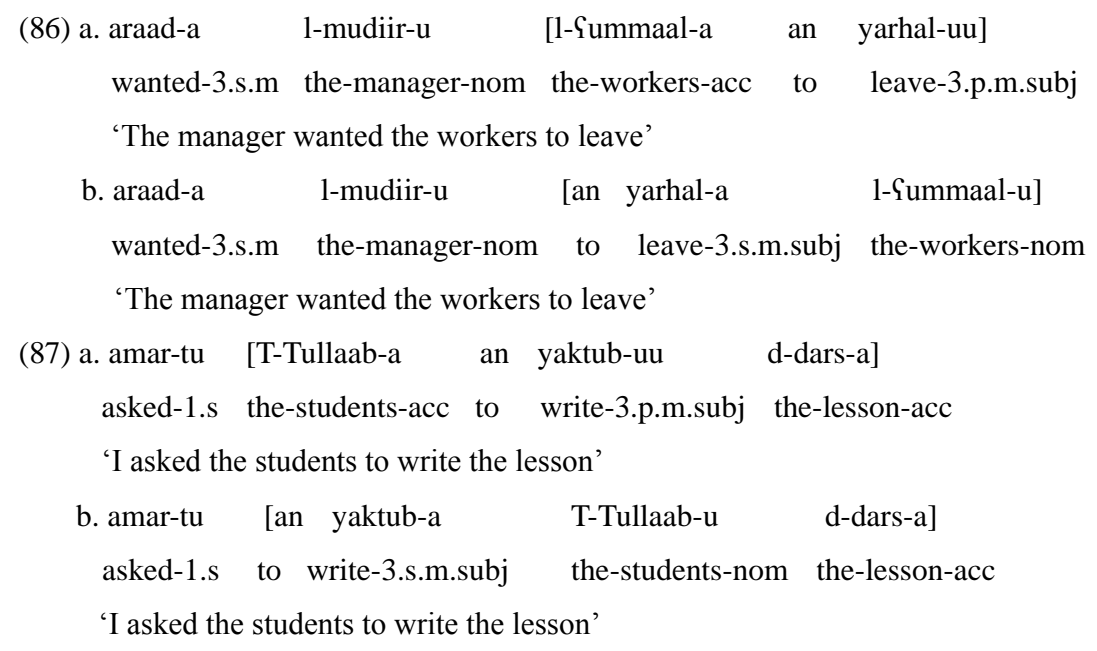

Sentences (a) in (63-64) show the embedded subjunctive complements with an SV word order and sentences (b) show the embedded subjunctive complements with a VS word order. In the embedded SV complements, the $\Phi$-complete head $\mathrm{T}$ establishes full agreement with the subject in-situ, and since the head T is $\Phi$-complete, it has an EPP feature to trigger the movement of the subject to spec-TP. In this position, i.e. spec of embedded TP, the probe of the matrix verb targets the embedded DP and assigns its Case as accusative.

In the embedded VS complements, the TP is $\Phi$-incomplete. The embedded T establishes partial agreement with its local subject, and since the $\mathrm{T}$ is $\Phi$-incomplete, it cannot have an EPP feature to raise the subject to spec-TP and the subject surfaces postverbally with a nominative Case.

\subsection{Complements of obviation structures}

Obviation structures are tenseless complements that obviate a matrix probe from accessing their local domain (Dalmi, 2005). Consequently, formal features in this type of embedded clauses are valued locally by a local defective probe. In standard Arabic, a class of matrix verbs, such as tamanna 'wished' and raghib 'desired', can subcategorise for a tenseless subjunctive clause of the obviation type that is headed by a $\Phi$-incomplete $\mathrm{T}$ (Soltan, 2007):

$$
\begin{aligned}
& \text { (88) a. atamanna-a an yahDur-a } \\
& \text { wish-1.s to come-3.s.m.subj the-guests-nom } \\
& \text { 'I wish the guests would come' }
\end{aligned}
$$




\section{Feras Saeed}

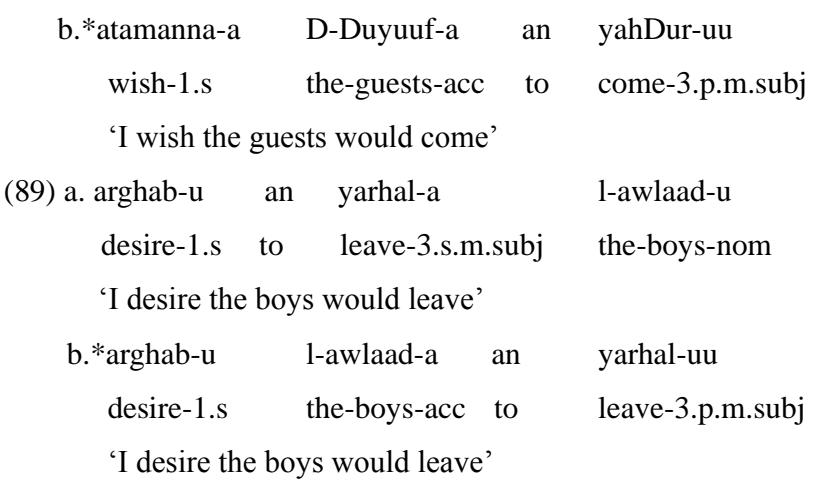

Tenseless clauses can be accessed by a matrix probe, however, the lexical properties of the matrix verbs in the class of predicates in (88-89) play an important role here since such verbs can only subcategorise for a complement that is headed by a $\Phi$-incomplete $\mathrm{T}$, forcing the embedded subject to stay in-situ where its nominative Case is assigned by the local T probe, and obviating the matrix $\mathrm{T}$ from targeting an argument in the embedded domain.

Therefore, I assume that in tenseless obviation structures in Standard Arabic the embedded $\mathrm{T}$ is always $\Phi$-incomplete; consequently the EPP feature is not triggered and the embedded subject stays in-situ in spec-vP. The defective $\mathrm{T}$ in the embedded clause sends a probe to value its formal features against the features of the embedded subject, establishing partial agreement with that DP and assigning the latter's nominative Case in-situ.

\section{Conclusion}

In this paper, I argue that the standard definition of defective probes seems to be problematic when applied to some data from Standard Arabic. In this language, defectivity of the probe corresponds to $\Phi$-incompleteness alone; and the tense of the clause does not affect the Case-agreement system. A tenseless probe in subjunctive complements in Standard Arabic can establish agreement with a DP goal and assign its Case. Embedded subjunctive verbs in this language inflect for agreement and show an asymmetrical behaviour, i.e. full vs. partial agreement with their subject DPs, depending on whether the subject surfaces preverbally or postverbally. The assumption that only $\Phi$-complete probes can assign structural nominative Case on the subject is shown to be unable to explain the Case-agreement facts in Standard Arabic and similar null subject languages. In these languages, nominative Case on the subject can be assigned in-situ by a $\Phi$-incomplete probe.

\section{References}




\section{The Case-agreement System in Subjunctive Complements}

Amritavalli, R. \& Jayaseelan, K.A. 2005. Finiteness and negation in Dravidian [A]. In G. Cinque \& R.S. Kayne (Eds.), The Oxford handbook of comparative syntax [C]. Oxford: Oxford University Press, 178-220.

Benmamoun, E. 2000. The feature structure of functional categories: A comparative study of Arabic dialects [M]. Oxford: Oxford University Press.

Cantarino, V. 1975. The syntax of Modern Arabic prose [M]. Bloomington: Indiana University Press.

Chomsky, N. 2000. Minimalist inquiries: The framework [A]. In R. Martin, D. Micheals, \& J. Uriagereka (Eds.), Step by step: Essays on minimalist syntax in honor of Howard Lasnik [C]. Cambridge, Mass.: MIT Press, 89-156.

Chomsky, N. 2001. Derivation by phase [A]. In M. Kenstowicz (Ed.), Ken Hale: A life in language [C]. Cambridge, Mass.: MIT Press, 1-52.

Chomsky, N. \& Lasnik, H. 1993. Principles and parameters theory [A]. In J. Jacobs, A. Von Stechow, W. Sternefeld \& T. Vennemann (Eds.), Syntax: An international handbook of contemporary research [C]. Berlin: Walter De Gruyter, 506-569.

Costa, J. 2001. Postverbal subjects and agreement in unaccusative contexts in European Portuguese [J]. The Linguistic Review, 18 (1):1-17.

Dalmi, G. 2005. The role of agreement in nonfinite predication [M]. Amsterdam: John Benjamins.

Fassi Fehri, A. 1993. Issues in the structure of Arabic clauses and words [M]. Dordrecht: Kluwer.

Harbert, W. \& Bahloul, M. 2002. Postverbal subjects in Arabic and the theory of agreement [A]. In J. Ouhalla \& U. Shlonsky (Eds.), Themes in Arabic and Hebrew syntax [C]. Dordrecht: Kluwer,45-70.

Ibn Aqiil, Bahaa-u-ddiin A. 14 ${ }^{\text {th }}$ century[1979]. Sharh alfiyyat Ibn Maalik [M]. Cairo: Daar Al-fikr.

Kayne, R. 1991. Romance clitics, verb movement, and PRO [J]. Linguistic Inquiry, 22:647-686.

Rizzi, L. 1997. The fine structure of the left periphery [A]. In L. Haegeman (Ed.), Elements of grammar: Handbook in generative syntax [C]. Dordrecht: Kluwer, 281-337.

Rizzi, L. 2004. On some properties of subjects and topics [Z]. Ms., University of Siene.

Ryding, K.C. 2005. A reference grammar of Modern Standard Arabic [M]. Cambridge: Cambridge University Press.

Siibawayh, Abu Bishr Q. $8^{\text {th }}$ century[1938]. Al-kitaab [M]. Bulaaq, Cairo.

Soltan, U. 2007. On formal feature licensing in minimalism: Aspects of Standard Arabic morphosyntax [D]. $\mathrm{PhD}$ thesis. University of Maryland, College Park.

Tallerman, M. 1998. Understanding syntax [M]. London: Edward Arnold.

Terzi, A. 1997. PRO and null case in finite clauses [J]. The Linguistic Review, 14:335-360. 